\title{
MIGRAÇÃO COMO CRIME, ÊXODO COMO LIBERDADE
}

\author{
Aryadne Bittencourt Waldely ${ }^{\top}$ \\ Fabrício Toledo de Souza ${ }^{2}$ \\ Matteo Louis Raul Meirelles Theubet ${ }^{3}$ \\ Natalia Cintra de Oliveira Tavares ${ }^{4}$ \\ Raísa Barcellos Nepomuceno ${ }^{5}$
}

"O problema é controlar todos esses movimentos
para além do grande abismo" (Pierrete Fleutiaux)

$\mathrm{O}$ tratamento securitário dispensado à migração - e aos deslocamentos em geral, incluindo o refúgio - não é excepcional nem secundário. Se a criminalização aparece como evento extraordinário, isso quer dizer apenas que as práticas de securitização não se limitam à punição e que não são exclusivas das instituições de repressão. Ao contrário, estão espalhadas por diversos dispositivos institucionais, práticas e discursos. No caso dos migrantes, refugiados e deslocados em geral, o que está em questão não é exatamente reprimir ou interditar, mas classificar os fluxos, os atos e os sujeitos e docilizar os corpos. E é a fuga em si mesma - seja o deslocamento voluntário ou não - que se torna objeto de tais dispositivos. Neste sentido, é preciso analisar e qualificar os eventos em relação à sua potência e à sua importância política: a criminalização e todos os atos de repressão, docilização e captura são reativos e secundários em relação à fuga; enquanto a fuga é o ato primeiro, o movimento antecedente e capaz de produzir liberdade, justiça e direitos.

Palavras-chave: refúgio, securitização, migração.

1 Mestranda em Teorias Jurídicas Contemporâneas do Programa de Pós-Graduação em Direito da UFRJ. Rio de Janeiro, RJ, Brasil.

2 Doutorando em Teoria do Estado e Direito Constitucional da PUC-Rio. Rio de Janeiro, RJ, Brasil.

3 Pós-Graduando em Ajuda Humanitária e ao Desenvolvimento da PUC-Rio. Rio de Janeiro, RJ, Brasil.

4 Mestranda em Teorias Jurídicas Contemporâneas do Programa de Pós-Graduação em Direito da UFRJ. Rio de Janeiro, RJ, Brasil.

5 Graduanda em Relações Internacionais, UFRJ. Rio de Janeiro, RJ, Brasil.

6 FLEUTIAUX, Pierrete. História do abismo e da luneta. 


\section{(In)Segurança, Território e População}

"Não vivemos num mundo destruído, vivemos num mundo transtornado. Tudo racha e estala como no equipamento de um veleiro destroçado" (Kafka) ${ }^{7}$

Em "História do abismo e da luneta" ${ }^{8}$, Pierrette Fleutiaux conta a história ficcional de um mundo dividido. De um lado, funcionários vigiam, de cima de muralhas, a ação dos homens que vivem do outro lado, sobre e além do abismo. A pequena história é narrada da perspectiva de um angustiado funcionário dotado de uma luneta composta, que lhe permite ver mais do que seus colegas. Enquanto seus colegas de lunetas mais simples identificam blocos de turbulências, o personagem principal é capaz de identificar os movimentos mais ínfimos e, desta forma, antecipar as agitações e explosões de rebeldia. Todos trabalham no propósito de vigiar as turbulências. Quando as insurgências parecem ameaçadoras, os funcionários colocam em funcionamento um grande dispositivo: uma lente enorme e colossal, que dispara um raio fulminante sobre as hordas rebeldes, separando-as em pequenos blocos, restaurando, assim, a normalidade.

A novela faz lembrar o panóptico de Jeremy Bentham, descrito e analisado por Michel Foucault em "Vigiar e Punir", com duas importantes diferenças: no panóptico, a questão não era exatamente distinguir os detalhes e antecipar eventuais convulsões da normalidade, mas tornar presente, durante todo o tempo, a sensação de vigilância e, desta forma, introduzir no sujeito observado o controle sobre si mesmo através da paranoia instaurada. Essa é a grandiosidade de sua arquitetura. E, além disso, o dispositivo panóptico não prevê uma ação que possa irromper as turbulências. Ou melhor, ele a dispensa ou pretende torná-la desnecessária, através de outra economia de poder. O que ele pretende é neutralizar, a partir do próprio sujeito vigiado, sua capacidade de sublevação.

As sociedades disciplinares, na forma como analisada e descrita por Foucault, deram lugar às sociedades de controle. E mesmo o panóptico se torna economicamente pesado. Se antes os confinamentos - escola, quartel, fábrica, prisão - se apresentavam como moldes, nas sociedades de controle, a normalização acontece por modulações. O sujeito não apenas contém em si os mecanismos de controle, mas é constituído mesmo como ponto de modulação do controle. Não há exatamente um fora de onde se o exerce. E o controle não se restringe a si mesmo, mas é controle alheio, ou melhor, expansão dos mecanismos de controle por toda a malha coletiva, como elemento das relações. A própria vida e conexão entre as pessoas se tornam objeto dos cálculos do poder.

\footnotetext{
KAFKA, Franz. A Grande Muralha da China.

8 FLEUTIAUX, op. cit.
} 
Os mecanismos de controle se expandem para além dos lugares de confinamento e as instituições de polícia não têm a exclusividade do controle e da punição, da mesma forma como as prisões e carceragens não são mais o principal ou único destino dos "desviantes", anormais ou marginais, ainda que o número de prisioneiros e de presídios não pare de aumentar e ainda que as forças de polícia sejam cada vez mais investidas com crescentes recursos e poder. Os poderes, aliás, se exercem em níveis variados e em diferentes pontos do tecido social. Nem mesmo se pode dizer que todos estes pontos - macros e micros - são criados ou absorvidos pelo Estado.

Funcionam como uma rede de dispositivos ou mecanismos a que nada ou ninguém escapa, e em relação à qual não existe exterior ou fronteira. Por isso Foucault afirma que o poder não é algo que se detém como uma coisa, como uma propriedade, que se possui ou não. Não existe essa distinção entre os que têm o poder, de um lado, e os que não o têm, de outro. O poder, em última instância, é algo que se exerce, como forma de relação e que, portanto, se efetua, funcionando como uma "maquinaria, como uma máquina social que não está situada em lugar privilegiado ou exclusivo"

A questão não é negar a existência, a autoridade nem tampouco a crueldade dos dispositivos punitivos tradicionais, muito menos o papel das instituições de Estado, mas de verificar outras formas mais sutis e diluídas de controle e dominação. Nisso, também verificar que a repressão é apenas um dos pontos da contenção. Em suas análises sobre o poder, Foucault já indicava que ele não é essencialmente repressivo e não está concentrado nas mãos de um pequeno grupo: atravessa toda a sociedade, passando tanto por aqueles que seriam os dominantes quanto pelos dominados e se produz como forma de relação. Não se trata sequer de decidir pela morte ou repressão dos indivíduos, mas de incluir a vida, como um todo, como objeto de interesse do poder.

No que diz respeito aos migrantes e refugiados, interpretados e classificados como o risco que vem de fora, o que os dispositivos de normalização e controle pretendem não é impedir os movimentos. Mais do que isso, eles visam normalizar os sujeitos e evitar a força irruptiva e subversiva que eles provocam, inclusive e sobretudo, atuando sobre as conexões entre os sujeitos, sobre suas redes de cooperação e sobre as individualidades. Assim, esses dispositivos produzem subjetividades, seja demarcando os limites da legalidade e da normalidade, seja impondo aos sujeitos a internalização da culpa ou ainda através da simples segregação.

Ao mesmo tempo, os mecanismos de poder justificam e ampliam sua própria capacidade de atuação. A demarcação do limite entre nacionais e estrangeiros, por exemplo, não funciona apenas para que se faça aplicar sobre estes últimos uma repressão específica ou um poder diferenciado. Trata-se de

9 FOUCAULT, Michel. Microfísica do Poder, p. XIV. 
criar condições para que se soterrem alteridades "ameaçadoras" e potenciais irrupções de insubordinação, mesmo no interior do que talvez se possa chamar de subjetividade do "nacional".

O "terrorista", que é sempre uma ameaça que vem de fora, por exemplo, não é apenas a justificativa para a ampliação dos investimentos em segurança e repressão nas fronteiras. A mesma atribuição de sentido se presta também a ampliar a própria definição de terrorista, ou melhor, da anormalidade que significa esta figura e tantas outras formas de rebeldia. É preciso, contudo, insistir que não se trata apenas de aumentar a possibilidade de repressão, ampliar o rol de tipos penais e o número de sujeitos encarceráveis. A mesma governamentalidade que cria exponencialmente centros de detenção para imigrantes indocumentados produz também conhecimento sobre estas figuras, isto é, o "saber" e a "verdade" sobre imigrantes e refugiados, sobre suas motivações e sobre suas estratégias. É o mesmo movimento em diferentes expressões.

As linhas que traçam as fronteiras de normalidade, aceitabilidade e desejabilidade, no entanto, não estão e nunca estiveram "fora". Aliás, é preciso desfazer-se deste mito sobre a alteridade que vem de fora, tanto quanto é preciso desfazer-se da ideia de uma alteridade definida fora da relação. A própria noção de alteridade só poderá ser formulada na relação e na negociação. Isso quer dizer que o "estrangeiro", o "imigrante" e o "refugiado" e todas as supostas características que os acompanham, inclusive quanto a sua nacionalidade, origem e especificidades, são figuras forjadas dentro de processos extremamente complexos e negociados. As linhas de irrupção que esta "alteridade" produz são também compostas por elementos que seriam "internos" ao terreno "nacional". Traços minoritários que atravessam todo o território causando desestabilizações e resistindo a capturas e opressões.

Um refugiado sírio, um migrante haitiano, uma estudante guineense: a definição de sua identidade e de sua "alteridade" será determinada na relação, na composição e no embate. E na produção de saber que faz parte das relações de poder. Da mesma forma, é preciso também se desfazer do mito segundo o qual os mecanismos de repressão e violência estatal recaem sobre os pontos de irrupção. Seja nas sociedades disciplinares ou de controle, ao poder e aos seus mecanismos de repressão nunca interessou apenas agir sobre aqueles pontos ou sobre os sujeitos que as fazem eclodir. Aos mecanismos de normalização interessa criar vastas redes - capilarizadas, descentralizadas e diluídas - de controle e sujeição, que possam prevenir e intimidar novas implosões, se possível, dentro da "alma" de cada sujeito.

É a fuga em si mesma, seja nomeada como deslocamento voluntário ou não, e justamente pelo desejo que a constitui, que se torna objeto dos dispositivos de controle: fugir é o crime que cometem os migrantes e os refugiados. Insubordinaram-se contra a exploração que os queria retidos num determinado território. Os dispositivos de segurança não são capazes de impedir esse 
movimento - os deslocamentos, os êxodos e as diásporas - mas estão investidos de poder para desativar o potencial subversivo que faz parte da fuga. Ou seja, os efeitos de poder da securitização, que está capilarizada em todo tecido social, dizem respeito a uma prática de docilização dos sujeitos que subvertem a lógica de fronteiras. Lógica essa que se remete a conjunto de normas, saberes e poderes que governam os dispositivos de segurança, os territórios e as populações.

\section{Deslocamentos e desestabilização}

$\mathrm{O}$ "perigo" provocado por imigrantes e refugiados encontra-se justamente no fato de que os deslocamentos operam desestabilizações, sobretudo em detrimento a esse esforço de docilização dos corpos. A fuga, a saída, o deslocamento em si e mesmo a chegada, são movimentos que rompem com as estruturas políticas, em âmbito nacional e internacional, organizadas tradicionalmente de forma hostil às migrações. Inevitavelmente, os migrantes e refugiados afetam os Estados pelas desestabilizações que eles provocam. Desestabilizar significa provocar a fragilidade de pilares básicos dos Estados, tais como "fronteira", "nacional" e "cidadania". Significa também colocar em xeque a condição material que é exercida desigualmente pelos sujeitos que ocupam o mesmo espaço. Desestabilizar significa, afinal, dialogar com relações de poder. Ocorre, porém, que a racionalidade governamental tende a atribuir um sentido negativo a essas desestabilizações.

Historicamente, o mito criacional dos Estados Unidos da América e o estabelecimento artificial dos Estados-nacionais na Europa mostram como a construção do Estado moderno foi fundamentado em conceitos forjados que permitem formar a ideia de uma unidade interna que deve estar fortalecida a fim de impedir a penetração de interferências externas. Contudo, essa noção de Estado se encontra mais no plano de abstração conceitual do que da existência material. As relações, as trocas e os intercâmbios não deixaram de ocorrer em termos de linguagem, cultura e subjetividades. Não cabe aqui explorar a formação do sistema internacional nos contornos contemporâneos, mas indicar que o esforço governamental por uma suposta estabilização interna tende a ser coadunável com as possibilidades de influência das relações e, particularmente, daquelas provocadas por imigrantes e refugiados, apenas na medida em que elas fortalecem a estrutura e não quando eles ensejam atualizações e adaptações.

Por um lado, os migrantes e refugiados provocam os deslocamentos a partir de forças de resistência e de subversão à razão de Estado que os limita. Por outro lado, essa mesma razão de Estado, que disciplina e controla os fluxos, é constituída por elementos de diferenciação e securitização. É uma governamentalidade que recorre a instrumentos de classificação e separação para fragmentar a noção (e a força) de um fluxo em prol da individualização do fenômeno migratório - e dos deslocamentos em geral - e, por conseguinte, da subjetivação. 
A condição de ser refugiado, migrante regular ou migrante indocumentado pauta os contornos das relações desses indivíduos pela subjetividade que lhes é imputada. Assim, o "duplo constrangimento" político opera com práticas simultâneas de individualização e totalização ${ }^{10}$. Quanto aos refugiados, a sua interlocução com os canais sócio-políticos ocorre mediante a atribuição constante de sentido do que é ser refugiado e de quem não pode ser considerado refugiado. Ao mesmo tempo que esse sentido é incorporado pelos refugiados, eles passam a se colocar nessa condição e a defender esse sentido, sobretudo nos canais da esfera estatal.

Deste modo, o reconhecimento jurídico do refugiado não se faz por um ato declaratório, como afirma a lei ${ }^{11}$. O reconhecimento da condição de refugiado pressupõe que o "candidato" possa ser visto como uma inocente vítima, desprovida de vontade e dependente de ajuda humanitária. A qualquer momento, seja na entrada no país, nas fases do processo administrativo de elegibilidade ou na vida social, a sua condição de ser refugiado está em risco. Se não é capaz de convencer sua condição de vítima inocente, por exemplo, ele pode ser classificado na categoria de imigrante indesejado, com os atributos que normalmente lhe atribuem, como mentiroso, criminoso ou subversivo.

Ao mesmo tempo, essas diferentes dinâmicas de constituição disparadas pelos deslocados e pelos sistemas governamentais se co-constituem numa relação permanente de ações que se induzem e se respondem umas às outras. Como diria Foucault, "mais do que analisar o poder do ponto de vista de sua racionalidade interna, consiste em analisar as relações de poder através do antagonismo das estratégias"12. Assim, para compreender os mecanismos de securitização e criminalização, não basta olhar apenas para a estrutura estatal. É fundamental ressaltar a potência dos deslocados, pois estes se utilizam das migrações e fugas para dialogar suas formas de resistência com o status quo, mas sempre criando um excedente incapturável, na forma de novas subjetividades, novas formas de vida ou novos direitos.

O desejo de fuga é, inclusive, imanente à força que faz mover. No caso dos refugiados, ao contrário da retórica tradicional, não há relação de exclusão entre necessidade de sobreviver e desejo de uma vida melhor. A despeito destas subjetividades, a governamentalidade vigente não legitima um migrante (e muito menos um fluxo) tão somente pela liberdade do desejo de fugir, migrar, mudar e superar. A fuga é capturada em classificações morais - como a imagem da vítima inocente do refugiado - inclusive apelando para razões "humanitárias" - por meio da imagem do migrante ou refugiado vulnerável - para transpor a lógica hostil do sistema internacional às migrações.

\footnotetext{
${ }^{10}$ FOUCAULT, Michel. Uma trajetória filosófica.

${ }^{11}$ De acordo com o art. 26 da Lei 9.474 de 1997, "a decisão pelo reconhecimento da condição de refugiado será considerada ato declaratório e deverá estar devidamente fundamentada".

${ }^{12}$ FOUCAULT, Uma trajetória filosófica, op. cit., p. 276.
} 
A distinção humanitária que define o sujeito refugiado, contudo, só é possível porque existe um conjunto maior de sujeitos criminalizados e securitizados. Não há contraposição entre perspectiva humanitária e securitizatória. Elas se relacionam e só existem uma em relação à outra. A questão que resta saber é qual seria a delimitação da fronteira humanitária.

Os Estados operam suas relações com os fluxos migratórios com base em práticas de classificação de deslocamentos e de adequação dos sujeitos. A identificação do perigo e da oportunidade nos deslocamentos é exercida menos por meio da burocracia e mais por um conjunto de práticas institucionais e cotidianas de diferenciação, classificação e hierarquização.

No Brasil, essas práticas podem ser encontradas no tratamento abusivo dispensado aos migrantes na Polícia Federal; nas discriminações sofridas pelos migrantes e refugiados negros durante o surto de Ebola ${ }^{13}$; na dificuldade de encontrarem trabalho digno onde não sejam severamente explorados; no tom em que a grande mídia aborda temas de migração e refúgio; nos critérios de elegibilidade para refúgio, etc. De toda sorte, não há culpa biográfica para as manifestações securitizatórias a respeito dos migrantes, justamente porque não há uma centralização do conjunto de forças que constitui o vocabulário de criminalização das migrações.

Para os Estados que agora são obrigados a lidar com aumentos significativos de fluxos de migrantes e refugiados, comoé o caso do Brasil, há uma certa apreensão quanto ao modo como o tema será tratado. O futuro dirá se a securitização é o único modo de acomodar a questão e se a criminalização dos refugiados e migrantes é um destino inescapável. Nem uma primorosa e sofisticada Lei de Refúgio (Lei 9.474/97), nem o projeto da Lei de Migração (PL 288) ${ }^{14}$ - que deve substituir o atual Estatuto do Estrangeiro (Lei 6.815/80) - afastam a perspectiva securitária totalmente, ainda que estejam longe das leis e práticas institucionais de outros países onde o tratamento aos refugiados e migrantes passa por centros de detenção e punição criminal.

Se no Brasil a criminalização dos refugiados e migrantes, na sua expressão mais tradicional, não se tornou ainda uma prática comum, isso não quer dizer

${ }^{13}$ No ápice da epidemia de Ebola, que atingiu de maneira mais grave três países africanos, a Polícia Federal do Rio de Janeiro negou atendimento a estrangeiros provenientes de sete diferentes países africanos, dentre os quais alguns que não contabilizaram um caso sequer da doença. $\mathrm{E}$ mesmo estrangeiros residentes há mais de um ano no Brasil foram impedidos de renovar seus documentos, em razão deste impedimento. Esta situação gerou um inquérito civil instaurado pelo Ministério Público Federal e se tornou tema de reunião do Comitê Estadual de Polícias Públicas para Refugiados e Migrantes, no Estado do Rio de Janeiro.

${ }^{14}$ O Projeto de Lei $n^{\circ} 288$ de 2013, apresentada pelo senador Aloysio Nunes Ferreira, em julho de 2013, trata sobre direitos e deveres do migrante e regula a entrada e estada de estrangeiros no Brasil, revogando, em parte, o Estatuto do Estrangeiro. Atualmente, o PL se encontra para apreciação da Comissão de Relações Exteriores e Defesa Nacional. 
que os dispositivos de controle e segurança não os tenham como alvo. E se a criminalização aparece como evento incomum ou excepcional, isso revela que a securitização, enquanto modo de gestão e classificação de populações e fluxos, não se ocupa de práticas estritas de repressão ou interdição. Além disso, que a securitização não é exclusividade das clássicas instituições de controle e repressão, como se costuma pensar.

É verdade que os migrantes e refugiados - como todos os nacionais que se encaixam no perfil "desviante" ou "perigoso", o que inclui os provenientes de países não desenvolvidos e os pobres em geral - ainda enfrentam tratamento diferenciado no sistema de justiça brasileiro - como, por exemplo, penas demasiadamente severas para as "mulas", condenadas como "traficantes internacionais" ou mesmo desvantagens em responder as acusações em liberdade - e também nos serviços públicos em geral, principalmente quando autoridades policiais são responsáveis pelo atendimento. De todo modo, a migração irregular ainda não constitui crime propriamente dito, assim como eventuais problemas referentes ao pedido de refúgio, com exceção de fraudes ou falsidades graves, não são destinados, em geral, ao direito punitivo.

A criminalização é um dos momentos deste agenciamento e os seus efeitos evidentemente repressivos são tão significativos quanto os efeitos produzidos na subjetividade e nas relações. No caso dos migrantes, refugiados e deslocados em geral, o que está em questão não é apenas reprimir ou interditar, mas classificar fluxos, atos e sujeitos e docilizar os corpos. Ainda que se possa dizer que os dispositivos securitários não têm intenções ou objetivos finais, eles fazem parte dos agenciamentos que classificam e produzem subjetividades.

Dispensar aos deslocados o tratamento securitário tem como pressuposto a mesma lógica binária do poder, na sua produção não repressiva (ou positiva), que é efetuar a distinção de normais e anormais: seja entre nacionais e não-nacionais, migrantes voluntários e involuntários, refugiados inocentes e migrantes "ilegais", etc. O que conta, afinal, é definir a identidade normal e normalizada e o limite que se pode e não se pode traçar. Ou seja, definir a linha ou os limites que podem acionar sucessivos dispositivos de controle e repressão. Se a criminalização, com todos os seus aparatos, incluindo o processo judicial ou administrativo, a detenção ou encarceramento, a condenação e a expulsão, são a forma mais brutal e violenta dos dispositivos de poder, isso não significa que sejam as únicas formas de controle e que não coexistam com outras, tão relevantes quanto.

Nesse sentido, a existência de dois sujeitos ou de duas classificações de sujeitos - refugiado e migrante econômico - não é fruto de uma distinção realizada sobre os fatos, mas produção mesmo dos fatos e produção, ao mesmo tempo, da distinção. Exercício de poder-saber e produção de verdade sobre o que são os refugiados e migrantes. Poder e saber se implicam mutuamente, pois 
não há relação de poder sem que se constitua um campo de saber, da mesma forma que todo saber constitui novas relações de poder.

O refugiado, apesar de ser a exceção no sistema de regulação do estrangeiro ou da falta de regulação - e justamente por isso - não está excluído da lógica de securitização: durante todas as etapas da solicitação de refúgio, existe uma incessante busca por incoerência e contradições. A racionalidade soberana de Estado de proteção das fronteiras não escapa ao refúgio. Somente à vítima perfeita é declarada sua condição de refugiada. Como Teresa Hayter ${ }^{15}$ destaca, os Estados continuam mantendo o discurso de que eles têm uma tradição de receber "refugiados genuínos", fazendo com que, dessa maneira, o ônus de comprovar sua "autenticidade" enquanto refugiado recaia no próprio solicitante.

Mesmo em relação ao refugiado, uma figura aparentemente imune à hostilidade dirigida aos migrantes, os dispositivos de segurança pretendem definir os limiares de normalidade. Eles atuam justamente sobre as imagens atuais que permeiam o universo do refúgio, em especial a figura do refugiado como indivíduo despolitizado. O refugiado é, neste sentido, uma vítima passiva merecedora de proteção.

E isto permeia todo o percurso do solicitante de refúgio. Desde o momento que faz seu pedido, o solicitante deve se adaptar às expectativas de um sistema que pretende produzir sua própria verdade e que introduz um meio de proteção - o refúgio - como medida excepcional dentro dos complexos sistemas de seleção migratória. Em outras palavras, o solicitante deve corresponder à imagem de vulnerabilidade e fragilidade que é construída em torno do instituto de refúgio.

Isso tudo porque a imigração é, de modo geral, pensada como um problema. Como afirma Didier Bigo ${ }^{16}$, o argumento de segurança transforma dificuldades estruturais em culpabilização de indivíduos, ainda que seja antecipando e generalizando seus riscos. Assim, o mesmo mecanismo de elegibilidade e proteção que serve para excluir os refugiados da racionalidade securitizadora sobre os imigrantes serve também para incluí-los nessa percepção a partir de construção de binarismos e de instrumentais de oposição.

\section{A comunidade imaginada contra as fantasias paranoicas}

"Ao lado do poder, há sempre a potência. Ao lado da dominação, há sempre a insubordinação" (Antonio Negri) ${ }^{17}$

Como demonstra Foucault, as relações de poder não se passam fundamentalmente nem ao nível da repressão, nem ao nível do direito, nem

\footnotetext{
${ }^{15}$ HAYTER, Teresa. No Borders: The Cast Against Immigration Controls, p. 8.

${ }^{16}$ BIGO, Didier. Security and Immigration Toward a Critique of the Governmentality of Unease.

17 NEGRI, Antonio. Exílio.
} 
tampouco da violência. É falso definir o poder como algo que diz "não", que interdita ou castiga. Ao contrário, como ele afirma, a dominação capitalista não seria capaz de se manter se fosse exclusivamente baseada na repressão. $\mathrm{O}$ poder produz e produz real, "domínios de objetos e rituais de verdade" e possui positividade, ou seja, eficácia produtiva o que explica, portanto, que ele tem o corpo como alvo ou objeto, mas não para supliciá-lo ou destruí-lo, e sim para aprimorá-lo, adestrá-lo, docilizá-lo e explorá-lo ${ }^{18}$.

Não se pode entender o poder apenas por sua função repressiva, pois o que interessa não é expulsar os indivíduos da vida social, interditá-los na produção social, mas gerir suas vidas, de forma que se possa extrair, em nível máximo, suas potencialidades. Ao mesmo tempo, o poder quer o aumento do efeito da potência dos corpos e a diminuição de sua capacidade de revolta e de resistência. Torná-los politicamente dóceis, minimizando os perigos políticos das insurreições e irrupções. O caráter relacional do poder implica que as próprias lutas contra seu exercício não possam ser feitas de fora, de um lugar exterior, já que nada está isento de poder. Toda luta é sempre uma forma de resistência dentro da própria rede de poder. Como onde há poder, há resistência, não se pode falar, igualmente, que exista o lugar fixo da resistência, mas, ao contrário, "pontos móveis e transitórios, também distribuídos pela malha social"19.

Mesmo frente às fronteiras e aos abismos ou mesmo frente a uma imensa rede de poder que também se nomadizou, as formas de resistência continuam atuando, sempre produzindo excedentes, em termos de uma vida mais ampla, de uma vida coletiva com mais conexões e cooperação e com inteligência. Toda fronteira é também o conjunto de outras vozes e narrativas dissonantes, irrupções dissidentes, enunciadas por mulheres, pelos loucos, pelos colonizados, pelos traços e grupos minoritários, incluindo aqueles que portam sexualidades e comportamentos constantemente policiados. Por tudo isso, Homi Bhabha diz que a "demografia do novo internacionalismo é a história da migração pós-colonial, as narrativas da diáspora cultural e política, os grandes deslocamentos sociais de comunidades camponesas e aborígenes, as poéticas do exílio, a prosa austera dos refugiados políticos e econômicos" 20 .

Os deslocamentos, trânsitos e fluxos contemporâneos, que denunciam um mundo todo em colapso, uma guerra generalizada e descentralizada, de diferentes intensidades - aqui uma ocupação militar "pacífica", ali, repressão de manifestantes com armas "não letais", acolá, um bombardeio com armas químicas - indicam também a crise convulsiva do Estado-Nação e das tradicionais formas de exploração e opressão. Tais deslocamentos, movidos não pela falta, mas pelo desejo

\footnotetext{
${ }^{18}$ FOUCAULT, Microfísica do Poder, op. cit., p. XVI.

19 Ibidem, p. XIV.

${ }^{20}$ Homi Bhabha apud PELBART, Peter Pal. Vida Capital, p. 118.
} 
e pela afirmação da vida - ainda que deixando para trás a mais brutal violência são capazes de criar novas comunidades, novas formas de relação, novos sentidos e "novas terras imaginadas" e, enfim, novos sujeitos. Trata-se, como diz Pelbart de um sujeito que "se forma nos entrelugares, nas fronteiras, na itinerância"21.

As crises e rupturas, assim como seus deslocamentos, podem dar lugar a novas comunidades, conectadas por outros valores que não às relações tradicionais, novas tendências de caráter nômade. Uma comunidade que desviando das proximidades familiares e nacionais, encontra-se, na própria mobilidade, novas formas de liberdade e, principalmente, novas formas de alteridade, que seja mais plural e antropofágica. Na tradição de Fernando Pessoa, uma relação de "outramento", que não significa a manutenção ou apaziguamento entre as diferenças - entre o eu e o outro - mas a capacidade de se deslocar mesmo de si, desprender-se da identidade e construir novas derivas ${ }^{22}$. Uma alteridade que supõe a autonomia em relação às maquinarias do Estado e do poder, ao mesmo tempo, imanente aos encontros e novas subjetividades.

\section{Êxodo, desejo e resistência}

"É impossível compreender como penetraram na capital, mas estão aqui, e a cada manhã parece aumentar seu número" (Kafka) ${ }^{23}$

Ao final da novela, o personagem de Pierrette Fleutiaux vê-se aliviado pela perda de sua luneta, que se quebra de modo irremediável: "Minha luneta está quebrada: um grito de viva!"24. Nunca mais forçado a vigiar, observar, vociferar. A luneta está quebrada e não há conserto: "Quando a gente não vê mais tão longe, a gente vê mais perto". Caminhando em direção ao abismo que observou por toda a vida, pelo o longo caminho até o outro, tem um encontro inesperado: as pessoas que passou a vida observando eram seus semelhantes, também eles observadores. E dentre eles, o seu duplo, um homem portador de uma luneta complexa como ele. E o abismo, como pode perceber, não era nada mais que uma imensa sombra sobre o terreno plano.

As máquinas de vigilância e controle estão espalhadas, disseminando a paranoia e produzindo binarismos, criando duplos. Máquinas binárias que definem e produzem classes sociais, idades, sexos (homem-mulher), criança-adulto, branco-negro, público-privado, dentro-fora (de nós), etc. ${ }^{25}$. Máquinas binárias cuja complexidade está ligada à sua capacidade de se chocar e se relacionar umas com outras. E que não cessam de produzir binarismos, indefinidamente: se não é

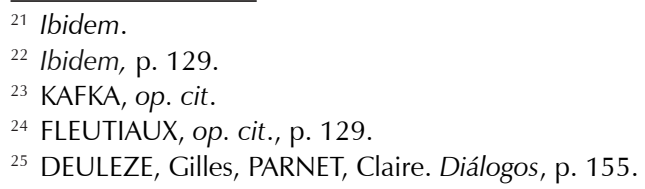


branco, nem negro, é mestiço; se não é homem, nem mulher, é travesti, e assim segue.

As linhas de irrupção, no entanto, também estão disseminadas, inclusive por dentro das muralhas dos impérios, como no conto de Kafka sobre a muralha da China $^{26}$. Peter Pál Pelbart ${ }^{27}$ faz observar que apenas os nômades, na sua circulação errática pelas fronteiras do Império, tinham noção da descontinuidade da muralha em construção. Viam as brechas e as lacunas, enquanto a população envolvida na construção da muralha ocupava-se na labuta árdua e diária, sem compreender a lógica das descontinuidades.

A grande muralha era construída em partes, pequenos pedaços, para que cada trabalhador não se desse conta que sua vida não seria suficiente para ver a obra terminada. Desta forma, seu desânimo não seria obstáculo para a obra. Sem corpo e nem identidade, a obra faz-se construir anonimamente, pelos braços e mentes dos trabalhadores, que buscam a segurança contra os bárbaros nômades que ameaçam o Império.

Os nômades, no entanto, já tinham avançado para dentro do Império e estavam acampados na praça central, diante do Palácio e seu número aumentava a cada dia. Enquanto o Império mobiliza todas as suas forças na construção da muralha, eles já estão instalados no coração da capital. E o Imperador torna-se ele mesmo um prisioneiro em seu palácio, ainda que os nômades não demonstrem qualquer intenção de tomá-lo. O que fazem é apenas infiltrar na cidade sua alteridade. As linhas de irrupção, como se vê, estavam desde sempre presentes.

De qualquer modo, interessa perceber como os migrantes e refugiados, em seu nomadismo territorial e subjetivo, são capazes de criar estratégias para sincretizar suas alteridades, produzir redes de colaboração e solidariedade e, enfim, construir formas de resistência e de liberdade. Mesmo que façam uso da imagem que lhes atribuem - como vítimas inocentes, pessoas vulneráveis, deslocados por razões humanitárias - é a potência do desejo que criou novas possibilidades de vida e de mundo.

\section{Referências Bibliográficas}

BIGO, Didier. Security and Immigration Toward a Critique of the Governmentality of Unease. Alternatives, v. 27, Special Issue, 2002, p. 63-92.

DELEUZE, Gilles. Post Scriptum sobre as Sociedades de Controle. In Conversações. São Paulo: Ed. 34, 1992.

DELEUZE, Gilles. Foucault. São Paulo: Brasiliense, 2005.

DELEUZE, Gilles; PARNET, Claire. Diálogos. Lisboa: Editora Relógio D'Água, 2004.

FLEUTIAUX, Pierrette. História do abismo e da luneta. In TADEU, Tomas (org.).

\footnotetext{
${ }^{26}$ KAFKA, op. cit.

${ }^{27}$ PELBART, op. cit.
} 
Quatro Novelas e um conto: As ficções do platô 8 de Mil platôs. Belo Horizonte: Autêntica Editora, 2014, p. 93-131.

FOUCAULT, Michel. Microfísica do Poder. Rio de Janeiro: Edições Graal, 1979.

FOUCAULT, Michel. Uma Trajetória Filosófica: Para além do estruturalismo. Rio de Janeiro: Forense Universitária, 2010.

FOUCAULT, Michel. Un Diálogo Sobre el Poder y otras conversaciones. Madrid: Alianza Editorial, 2012.

HAYTER, Teresa. No Borders: The Cast Against Immigration Controls. Feminist Review: Exile and Asylum: Women Seeking Refuge in 'Fortress Europe', Hampshire, Reino Unido, n. 7, 2003, p. 6-18.

JANOUSH, Gustav. Conversas com Kafka. Rio de Janeiro: Nova Fronteira, 1983.

NEGRI, Antônio. Exílio. São Paulo: lluminuras, 2001.

KAFKA, Franz. A Grande Muralha da China. Lisboa: Europa-América, 1975.

PELBART, Peter Pal. Vida Capital: Ensaios de biopolítica. São Paulo: Ed. Iluminuras, 2003.

\section{Abstract}

\section{Migration as a crime, exodus as freedom}

The security treatment given to migration and to displacements in general, including refuges, is neither especial nor secondary. If criminalization appears as an extraordinary event, that only means that securitizing practices are not limited to the punishment, and are not exclusive of the institutions of repression. In fact they are spread on institutional devices, practices and speeches. Concerning migrant cases, refugees and, displaced people in general, the point is not exactly to suppress or to ban, but classify the flows, acts, subjects, and turn the bodies docile. It is the flight itself whether the movements are volunteers or not - that becomes subject of these devices. On these terms it is necessary to analyze and qualify events in relation to the potency and its political importance: the criminalization and all the repression acts, docile bodies and the capture are reactive and secondary in relation the flight itself. The flight is the first act, the preceding act, able to produce liberty, justice, and rights.

Keywords: refuge, security, migration.

Recebido para publicação em 30/06/2015

Aceito para publicação em 22/10/2015

Received for publication in June, $30^{\text {th }}, 2015$ Accepted for publication in October, 22 ${ }^{\text {th }}, 2015$

ISSN impresso 1980-8585

ISSN eletrônico 2237-9843

http://dx.doi.org/10.1590/1980-85852503880004512 